\title{
Erratum to: Evaluation of serum HER2-ECD levels in patients with gastric cancer
}

Katsunobu Oyama $\cdot$ Sachio Fushida $\cdot$ Tomoya Tsukada $\cdot$ Jun Kinoshita $\cdot$ Toshifumi Watanabe $\cdot$ Masatoshi Shoji $\cdot$ Shinichi Nakanuma $\cdot$ Koichi Okamoto $\cdot$ Seisho Sakai $\cdot$ Isamu Makino $\cdot$ Keishi Nakamura $\cdot$ Hironori Hayashi Masafumi Inokuchi $\cdot$ Hisatoshi Nakagawara $\cdot$ Tomoharu Miyashita $\cdot$ Hidehiro Tajima $\cdot$ Hiroyuki Takamura Itasu Ninomiya $\cdot$ Hirohisa Kitagawa $\cdot$ Takashi Fujimura $\cdot$ Ryousuke Tajiri $\cdot$ Akishi Ooi $\cdot$ Tetsuo Ohta

Published online: 21 May 2014

(C) Springer Japan 2014

\section{Erratum to: J Gastroenterol}

DOI 10.1007/s00535-014-0941-3

In Table 1 of this article, under the heading "Age", "<66" should be " $>66$ ". Also, under the final heading, "Tissue HER2 status", the two values shown (two each) in the columns for "Serum HER2 negative $(n=140)$ " and "Serum HER2 positive $(n=10)$ " were transposed. The correct table is shown as follows.
The online version of the original article can be found under doi:10.1007/s00535-014-0941-3.

K. Oyama $\cdot$ S. Fushida $(\bowtie) \cdot$ T. Tsukada $\cdot$ J. Kinoshita

T. Watanabe $\cdot$ M. Shoji $\cdot$ S. Nakanuma $\cdot$ K. Okamoto

S. Sakai · I. Makino - K. Nakamura ·

H. Hayashi - M. Inokuchi - H. Nakagawara - T. Miyashita ·

H. Tajima $\cdot$ H. Takamura $\cdot$ I. Ninomiya $\cdot$ H. Kitagawa $~$

T. Fujimura $\cdot$ T. Ohta

Department of Gastroenterologic Surgery, Kanazawa University,

13-1 Takara-machi, Kanazawa, Ishikawa 920-8641, Japan

e-mail: fushida@staff.kanazawa-u.ac.jp

K. Oyama

e-mail: oya-ma@staff.kanazawa-u.ac.jp

R. Tajiri · A. Ooi

Department of Molecular and Cellular Pathology, Kanazawa

University, Kanazawa, Ishikawa 920-8641, Japan
Table 1 Correlation between serum HER2-ECD levels and clinicopathologic variables

\begin{tabular}{|c|c|c|c|}
\hline Variables & $\begin{array}{l}\text { Serum HER2 } \\
\text { negative }(n=140)\end{array}$ & $\begin{array}{l}\text { Serum HER2 } \\
\text { positive }(n=10)\end{array}$ & $P$ value \\
\hline Age (range 27-86) & & & 0.054 \\
\hline$>66(n=75)$ & 67 & 8 & \\
\hline$\leq 66(n=75)$ & 73 & 2 & \\
\hline Gender & & & 0.282 \\
\hline Male $(n=107)$ & 98 & 9 & \\
\hline Female $(n=43)$ & 42 & 1 & \\
\hline Clinical stage & & & 0.610 \\
\hline Stage $1(n=56)$ & 53 & 3 & \\
\hline Stage $2(n=17)$ & 16 & 1 & \\
\hline Stage $3(n=17)$ & 17 & 0 & \\
\hline Stage $4(n=46)$ & 41 & 5 & \\
\hline Recurrence $(n=14)$ & 13 & 1 & \\
\hline$T$ & & & 0.819 \\
\hline $1(n=51)$ & 47 & 4 & \\
\hline $2(n=11)$ & 11 & 0 & \\
\hline $3(n=27)$ & 26 & 1 & \\
\hline $4(n=47)$ & 43 & 4 & \\
\hline$N$ & & & 0.245 \\
\hline $0(n=61)$ & 58 & 3 & \\
\hline $1(n=21)$ & 21 & 0 & \\
\hline $2(n=25)$ & 23 & 2 & \\
\hline $3(n=29)$ & 25 & 4 & \\
\hline$M$ & & & 0.702 \\
\hline $0(n=120)$ & 114 & 6 & \\
\hline $1(n=16)$ & 13 & 3 & \\
\hline Lauren's classification & & & 0.526 \\
\hline Intestinal $(n=73)$ & 67 & 6 & \\
\hline Diffuse $(n=77)$ & 73 & 4 & \\
\hline Tissue HER2 status & & & $<0.001$ \\
\hline Negative $(n=125)$ & 124 & 1 & \\
\hline Positive $(n=25)$ & 16 & 9 & \\
\hline
\end{tabular}


On the graph in Fig. 2, the labels for the symbols for "Non-responder" and "Responder" were transposed. The correct figure is shown as follows.

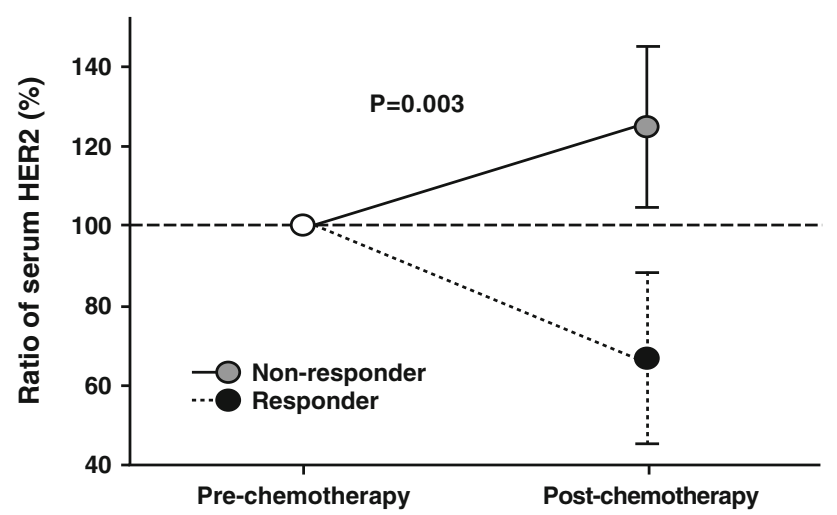

